\title{
Microliter per Kilogram per Day
}

National Cancer Institute

\section{Source}

National Cancer Institute. Microliter per Kilogram per Day. NCI Thesaurus. Code

C132481.

A unit of volume expressed as a number of microliters of the constituent per kilogram of weight per day. 